\title{
Cytological and Histomorphological Correlation of Salivary Gland Lesions: An Experience At Rural Tertiary Healthcare Hospital
}

\author{
Thangam R $\mathbf{R}^{1}$, Vaishali Dhananjay Kotasthane ${ }^{1 *}$, Dhananjay Shrikant Kotasthane ${ }^{1 *}$, Koteeswaran $\mathbf{G}^{1}$ and Kannan N S \\ ${ }^{1}$ Department of Pathology, Mahatma Gandhi Medical college and Research Institute, Pillaiyarkuppam, Pondicherry, India \\ ${ }^{2}$ Department of General Surgery, Sri Manakula Vinayagar Medical College and Hospital, Pondicherry, India
}

\section{ABSTRACT}

Background: Salivary gland tumours account for 3-10\% of all the head and neck neoplasm. FNAC is being increasingly used in the diagnosis of salivary gland tumours. The objective of this study was to evaluate the age, sex and site distribution and to evaluate the diagnostic accuracy of fine needle aspiration cytology (FNAC) in various salivary gland lesions in correlation with their histopathology, which helps in appropriate management of the patient.

Methods: The present study was done at the pathology department, Mahatma Gandhi Medical College and Research Institute, Pondicherry. FNAC was done using 22 gauge needle and $10 \mathrm{ml}$ syringe and smears were stained with H\&E and Giemsa stains. Histopathology was assessed on routine H\&E stained paraffin sections .Cyto-histo correlation was done and overall diagnostic accuracy, sensitivity and specificity were calculated.

Results: The study was conducted on 122 patients having salivary gland lesions . The age ranged from 24-80 years. Benign tumours were common in 3rd decade, whereas malignant tumours in 6th decade of life. There was female preponderance with male to female ratio of 1:1.03.Parotid glands were commonly involved in 74(78.72\%).Out of 94 neoplastic cases,78(82.97\%)were benign and $14(14.89 \%)$ were malignant. Pleomorphic adenoma was the commonest lesion observed accounted for $68.08 \%$.

Conclusion: The Overall sensitivity, specificity and diagnostic accuracy were $80 \%, 94.74 \%$ and $91.66 \%$ respectively. FNAC of the salivary gland is safe, rapid , accurate and reliable technique in the primary diagnosis of salivary gland lesions and useful in avoiding surgery (in inflammatory lesions) or limiting surgical procedures(in benign tumours).

Keywords: Fine Needle Aspiration Cytology, Histopathology, Salivary Glands

\section{Introduction}

FNAC (Fine needle aspiration cytology) has an important role in diagnosis of salivary gland lesions. The salivary glands are subjected to multiple diseases. Hence salivary glands diseases create an inquisitive group of lesions for investigation. The salivary gland tumours accounts for about 6 percentage of tumours in the head and neck region. ${ }^{[1]}$

FNAC of salivary gland tumour is accurate, tolerated and harmless to subjects. ${ }^{[2]}$ Its easy accessibility makes FNAC a popular method for evaluation of tumours of salivary gland. ${ }^{[3]}$ There is widespread acceptance of importance of FNAC in diagnosis of salivary gland lesions. ${ }^{[4]}$ Biopsies or frozen sections of salivary tumours taken for treatment planning carries risk of bleeding, facial nerve injury or inflammation compared to FNAC where complications are very negligible. ${ }^{[4,5]}$

In the present study, the utility of Fine Needle Aspiration Cytology in the diagnosis of salivary gland tumors is studied by correlating the cytological findings with the histopathological features which helps in early diagnosis and effective therapeutic approach

\section{Materials and Methods}

The study was undertaken after approval of Institutional Human Ethical Committte.This is a study of fine needle aspiration of 122 salivary gland lesions. All neoplastic and non neoplastic lesions of salivary gland involving major and minor salivary glands in various sites were studied. The relevant clinical details were noted from the accompanying requisition forms and/or the patient case records. These included age, gender and location and clinical diagnosis. FNAC was done using 22 gauge needle and $10 \mathrm{ml}$ syringe and the smears were wet fixed in isopropyl alcohol for Hematoxylin-Eosin and PAP stains and air-dried for Giemsa stains. Histopathology of the lesions, which were subjected to biopsy, was assessed on routine Haemotoxylin and Eosin stained paraffin sections.Cyto-Histological correlation was done and overall diagnostic accuracy,sensitivity and specificity was calculated.

\section{Results}

Fine Needle Aspiration was conducted on a total of 122 cases of lesions of salivary gland. The following observations were made. The patient age ranged from 11 
years to 80 years and the maximum number of cases were in the age group of 41-50years $(29.5 \%)$, followed by 31 $40 y r s(13 \%)$ and 51-60yrs(12\%).

Gender Distribution of Salivary Gland Lesions: In the present study, a female predilection was seen. Among the 122 cases studied, 62 cases $(50.82 \%)$ were females and 60 cases $(49.18 \%)$ were males. The female to male ratio was 1.03

Site Distribution of Salivary Gland Lesions: In the present study, the parotid gland $(75.40 \%)$ was the commonest site involved followed by submandibular gland $(22.95 \%)$ and minor salivary glands $(1.65 \%)$

Cytological Findings in Various Salivary Gland Lesions: Out of the 122 cases of salivary gland swellings, $26(21.3 \%)$ were non-neoplastic lesions and 96 (78.7\%) were diagnosed as neoplastic lesions. Among the salivary gland lesions, neoplastic lesions 96 (78.7\%) were more common and among the neoplastic lesions, benign $80(83.3 \%)$ were more common. Malignant tumours comprised $16.66 \%$ (16 cases).

Frequency and Site Distribution of Tumours of Salivary Gland: In the present study, the most common site of involvement of salivary gland tumour was parotid gland (78.72\%) and second most frequent site was submandibular gland (21.27\%). (Table1)
Among the benign tumours, parotid was the most common site $(82.5 \%)$ followed by submandibular gland $(17.5 \%)$. Malignant tumours equally involved parotid gland and submandibular gland..(Table 1)

Parotid gland was more commonly involved in neoplastic lesions as compared to other salivary glands and this was found to be statistically significant. $(p=0.0274)$ (Table 1$)$

Distribution of Neoplastic Lesions: Among the benign tumours, Pleomorphic Adenoma was the most common; accounting for $66.66 \%$ of all tumours and Warthin's tumour was the second most common benign tumour constituting $6.25 \%$ of all tumours. (Table 2 )

Mucoepidermoid Carcinoma was the most common malignant tumour constituting $12.50 \%$ of all tumours and Adenoid Cystic Carcinoma and Adenocarcinoma - NOS type were the second most common malignant tumours constituting $2.08 \%$ of all tumours .(Table:2)

Cyto-Histo Correlation of Salivary Gland Lesions: Out of 122 lesions, Histopathological correlation was available in forty-eight cases, It is shown in Table 3.

The parameters calculated showed sensitivity as $80 \%$, specificity as $94.74 \%$, Positive predictive value as $80 \%$, Negative predictive value as $94.74 \%$, Diagnostic accuracy as $91.66 \%$.

Table 1: Percentage frequency and site distribution of tumors of salivary gland.

\begin{tabular}{|c|c|c|c|}
\hline & Total no: & Benign & Malignant \\
\hline Parotid & $37(78.72 \%)$ & $33(82.5 \%)$ & $4(50 \%)$ \\
\hline submandibular & $10(21.27 \%)$ & $6(17.5 \%)$ & $4(50 \%)$ \\
\hline Minor salivary gland & $1(2.12)$ & $1(2.56)$ & 0 \\
\hline Total & $\mathbf{4 8}$ & $\mathbf{4 0}$ & $\mathbf{8}$ \\
\hline
\end{tabular}

Chi square $\left(x^{2}\right)=6.3752 ; p=0.0411 ; p<0.05, s=$ significant

Table 2: Distribution of neoplastic lesions.

\begin{tabular}{|c|c|c|}
\hline Cytological diagnosis & No. of cases & 66.66 \\
\hline Pleomorphic adenoma & 64 & 6.25 \\
\hline Warthin's tumor & 6 & 10.41 \\
\hline DD:Pleomorphic adenoma/Myoepithelioma & 10 & 12.5 \\
\hline Mucoepidermoid carcinoma & 12 & 2.08 \\
\hline Adenoid cystic carcinoma & 2 & 2.08 \\
\hline Adenocarcinoma NOS & 2 & 100 \\
\hline TOTAL & 96 & 2 \\
\hline
\end{tabular}


Table 3: Cyto-Histo Correlation of Salivary Gland Lesions.

\begin{tabular}{|c|c|c|c|c|c|c|c|}
\hline \multirow[b]{2}{*}{ Cytological diagnosis } & \multicolumn{7}{|c|}{ Histopathological diagnosis available } \\
\hline & $\begin{array}{l}\text { Chronic } \\
\text { sialadenitis }\end{array}$ & $\begin{array}{l}\text { Pleomorphic } \\
\text { adenoma }\end{array}$ & $\begin{array}{l}\text { Basal cell } \\
\text { adenoma }\end{array}$ & $\begin{array}{l}\text { Warthin's } \\
\text { tumor }\end{array}$ & $\begin{array}{l}\text { Mucoepider- } \\
\text { moidcarcinoma }\end{array}$ & $\begin{array}{c}\text { Adenoid cystic } \\
\text { carcinoma }\end{array}$ & Total \\
\hline Chronic sialadenitis $(n=24)$ & & & & 4 & & & 4 \\
\hline $\begin{array}{c}\text { Myoepithelioma/ } \\
\text { Pleomorphic adenoma }(n=10)\end{array}$ & & 4 & & & & & 4 \\
\hline Pleomorhic Adenoma $(n=64)$ & & 24 & & & 2 & 2 & 28 \\
\hline Warthim's tumor $(n=6)$ & & & & 2 & & & 2 \\
\hline $\begin{array}{c}\text { Mucoepidermoid carcinoma } \\
(\mathrm{n}=12)\end{array}$ & & 2 & & & 8 & & 10 \\
\hline Total & & 30 & 0 & 6 & 10 & 2 & 48 \\
\hline
\end{tabular}

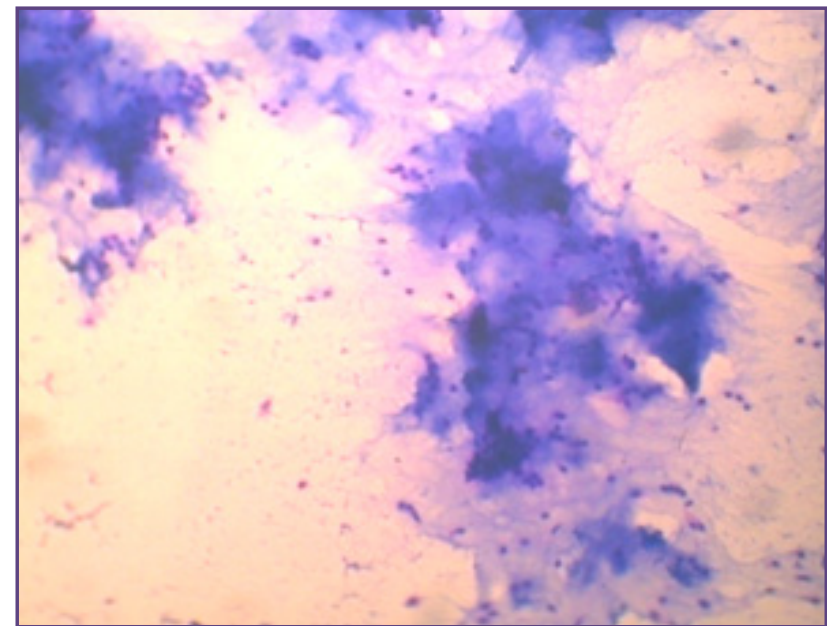

Fig. 1: FNAC of pleomorphic adenoma-Epithelial and myoepithelial cells in a chondromyxoid background (H\&E x 10).

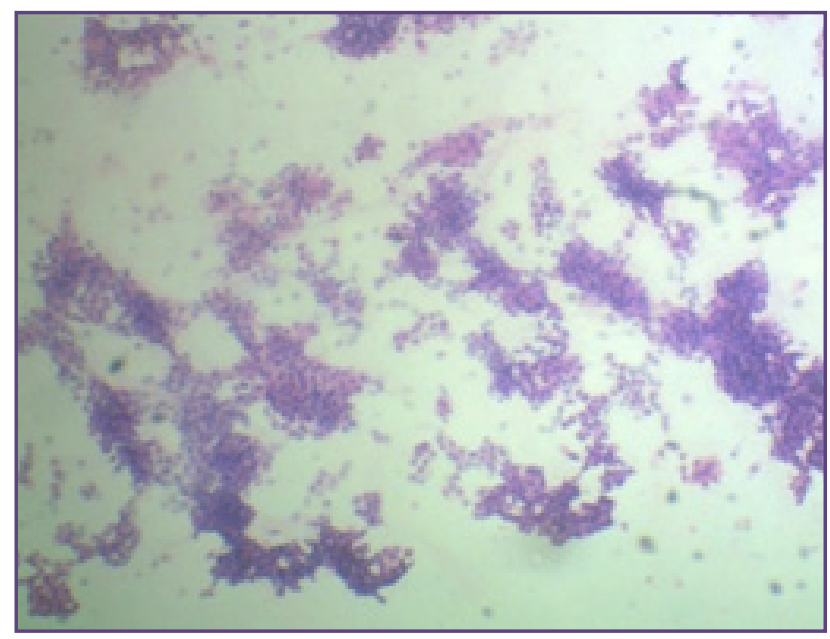

Fig. 3: FNAC of Mucoepidermoid carcinoma-clusters of squamous cells in a mucoid background (H\&Ex10).

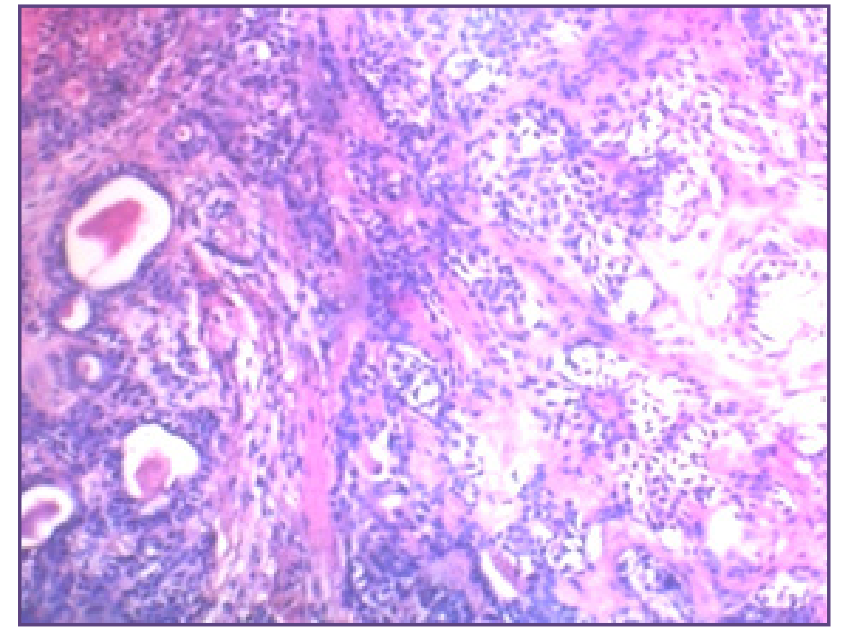

Fig. 2: HPE-Pleomorphic adenoma with chondroid differentiation [10x H\&E].

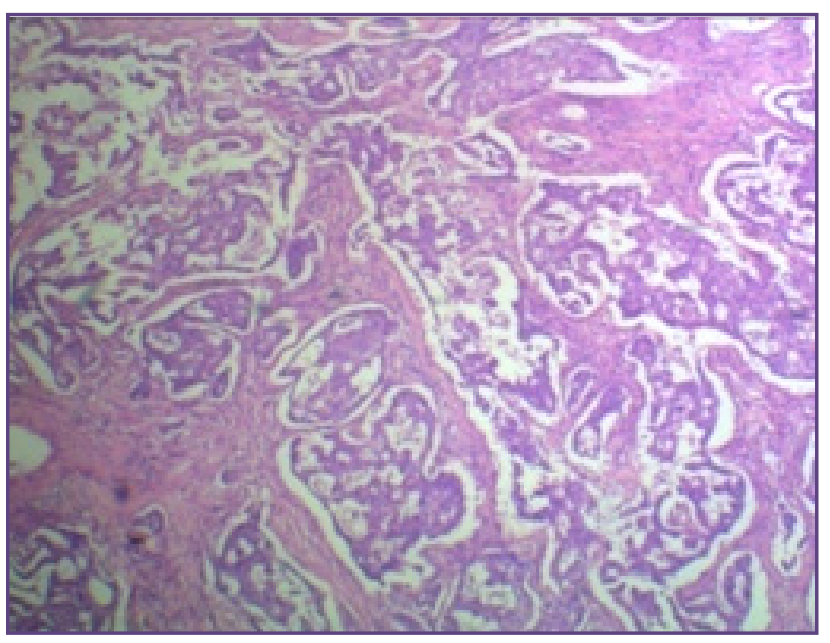

Fig. 4: HPE of Mucoepidermoid cells-intermediate squamoid cells (H\&E x10). 


\section{Discussion}

Fine needle aspiration gives useful information compared to other diagnostic techniques. The open biopsy gives an accurate diagnosis but it has a disadvantage of contaminating the operative field with tumour cells and difficulty in subsequent surgical management. The main objective of fine needle aspiration is to find if the mass is neoplastic or non neoplastic and in neoplastic whether it is benign or malignant. This preoperative diagnosis about the tumor type can be helpful to plan the best surgical approach.

Though, some complications with fine needle aspirations have also been rarely found such as pain, infection, tumour seeding, bleeding and tumour necrosis, they do not usually compromise the accurate diagnosis by histology except sometimes the infarction rarely obscure the diagnosis. ${ }^{[6,7]}$ Another issue encountered is inadequate aspiration and poor cellularity. ${ }^{[8]}$ Ultrasound guided aspiration may be helpful in obtaining better aspirate and decrease the number of unsatisfactory smears. ${ }^{[8]}$ The salivary gland lesions have overlapping morphological patterns in many of the benign and malignant neoplasms of the salivary gland. This makes them one of the difficult areas in cytopathology.

In the present study, Pleomorphic Adenoma and Mucoepidermoid Carcinoma were the most common benign and malignant tumours respectively as observed by other authors. These findings were similar to other studies. ${ }^{[7,9]}$

The most common diagnosis made in our study was Pleomorphic Adenoma as observed in other studies. ${ }^{[9]}$ Twenty eight cases were available for histopathological correlation.(Figures 1,2) Out of which twenty four turned out to be pleomorphic adenoma, two as Mucoepidermoid Carcinoma and two to be Adenoid Cystic Carcinoma on histology . Two cases diagnosed as Pleomorphic Adenoma in FNAC turned out to be Adenoid cystic carcinoma in histopathology. Distinction of highly cellular Pleomorphic Adenoma from Adenoid cystic carcinoma in cytology is not always easy. The stroma of adenoid cystic carcinoma was locally fibromyxoid and occasionally hyaline stromal globules seen were mistaken for Pleomorphic Adenoma. With H\&E and PAP, the globules are pale, semitranslucent and less conspicous. But specific to pleomorphic adenoma is true chondromyxoid stromal matrix with spindle cells. Accurate diagnosis of adenoid cystic carcinoma may be difficult in poorly differentiated tumors due to lack of characteristic stromal matrix. ${ }^{[10,11,12]}$

The second most common benign tumor after Pleomorphic Adenoma was Warthin's tumour.The three main components for diagnosis are lymphocytes, oncocytes and a dirty background. In our study, two cases were available for histopathological correlation with $100 \%$ concordance. ${ }^{[13]}$
Myoepithelioma (myoepithelial adenoma) may be plasmacytoid, epitheloid or spindle cell type.The cellular pleomorphic adenoma may not be distinguisable from myoepithelioma where selective sampling of solid focus of plasmacytoid cells without specific stroma has been done. In our study, four cases were given differential diagnosis of Pleomorphic Adenoma/Myoepithelioma turned out to be Pleomorphic Adenoma in histology. The plasmacytoid cells of pleomorphic adenoma is difficult to distinguish from Myoepithelioma -plasmacytoid variant. ${ }^{[14]}$

The most common malignant neoplasm is Mucoepidermoid Carcinoma.(Figures 3,4) our study as well as the study conducted by other authors. ${ }^{[11,15,16]}$ Low grade Mucoepidermoid Carcinoma is difficult to diagnose as malignant in FNAC and is one of the most common source of false negative results. The main cause for this is that many of these tumors are predominantly cystic. In our study eight cases were confirmed by histopathology and two which were diagnosed as Mucoepidermoid carcinoma histologically on cytology turned out to be Pleomorphic adenoma on histology. In these two false negative cases, the aspirate was hypocellular with mainly mucoid secretion which was mistakened for myxoid background of Pleomorphic Adenoma.The background should be checked for cohesive epithelial cells that gives clue to the diagnosis of low grade MEC and should lead to assiduous search for more diagnostic components. ${ }^{[1]]}$ The high or intermediate grade tumors can be accurately diagnosed by FNAC whereas low grade tumors gives unsatisfactory results as suggested by Klijanienko et al. ${ }^{[1]}$

The second most common malignant tumor was adenoid cystic carcinoma after Mucoepidermoid Carcinoma. FNA smears usually shows epithelial cells and acellular basement membrane material. This material is seen as homogenous spherical structures. The hyaline stromal globules seen in Adenoid cystic carcinoma should be distinguished from that seen in Pleomorphic Adenoma as well as mentioned by other authors. The cytological difference between two tumors can be done if smears are cellular so that distinguising relationship between Pleomorphic Adenoma and extracellular matrix can be recognised. ${ }^{[16]}$ The plasmacytoid cells seen in Pleomorphic Adenoma have abundant cytoplasm compared to the tumor cells of adenoid cystic carcinoma. ${ }^{[17,18]}$

Four cases of Chronic Sialadenitis which were diagnosed by FNAC were operated and turned out to be Warthin's tumor histologically. In predominantly cystic Warthin's tumor, obtaining diagnostic material may be very difficult. Both lymphoid cells and oncocytic cells must be recognised for accurate diagnosis, but either component may be sparse, absent or hidden by mucoid debris. In our case, oncocytic component was absent, which lead to erroneous diagnosis of chronic sialadenitis cytologically 
In the present study the Diagnostic accuracy, Sensitivity and specificity was $91.66 \%, 80 \%$ and $94.74 \%$ This was similar to studies by other authors. ${ }^{[9,19]}$

Despite earlier studies that reported a greater percentage of false-positive results than expected, more recent studies reports greater diagnostic accuracy and lesser sampling errors. The false-positive rates reported in the literature range from 0 to $10 \%$ and the accuracy increases with the experience of the pathologist. In our series, the percentages of false positive cases were $4.16 \%$. By using fine needle aspiration as a primary diagnostic tool in salivary gland masses, the number of patients undergoing surgery can be reduced. ${ }^{[20,21]}$

\section{Conclusion}

In patients with salivary gland neoplasm, fine needle aspiration cytology has very useful role in making preoperative diagnosis and management. Most of the benign and malignant neoplasm can be diagnosed with high level of accuracy with adequate sampling and good quality smear preparation. The high accuracy, sensitivity, and specificity of FNAC confirm that preoperative cytology is a useful, quick, reliable diagnostic technique for rapid and early diagnosis and we also conclude that it is simple and costeffective diagnostic tool suitable for developing countries.

\section{References}

1. Stenner M, Klussmann JP. Current update on established and novel biomarkers in salivary gland carcinoma pathology and the molecular pathways involved. Eur Arch Otorhinolaryngol. 2009 Mar. 266(3):333-41.

2. Zbaren P, Nuyens M, Loosli H, Stauffer E. Diagnostic Accuracy of fine needle aspiration cytology and Frozen section in primary parotid carcinoma. Cancer 2004;9(100):1876-81.

3. Nanda S KD, Mehta A, Nanda J. Fine needle aspiration cytology: a reliable tool in the diagnosis of salivary gland lesions. Journal of oral pathology \& medicine 2012;41(1):106-112.

4. Wong DSY, Li GKH. The role of fine-needle aspiration cytology in the management of parotid tumors: a critical clinical appraisal. Head Neck 2000; 22:469-473.

5. Zbaren P, Schar C, Hotz MA, Loosli H. Value of fine-needle aspiration cytology of parotid gland masses. Laryngoscope 2001;111:1989-1992.

6. Rau AR, Pai RR, Nayak S. Infarction of acinic cell carcinoma in a patient infected with HIV: A complication of fine-needle aspiration cytology obscuring definitive diagnosis. Diagn Cytopathol 2001; 24: 301-303.
7. Pabuccuoglu HU, Lebe B, Sarioglu S, Lebe E. Infarction of pleomorphic adenoma: A rare complication of fine-needle aspiration obscuring definitive diagnosis. Diagn Cytopathol 2003; 29: 222-224.

8. Shintani S, Matsuura H, Hasegawa Y. Fine needle aspiration of salivary gland tumors Int J Oral Maxillofac Surg 1997; 26: 284- 286.

9. Ahmad S, Lateef M, Ahmad R. Clinicopathological study of primary salivary gland tumors in Kashmir. JK- Practitioner 2002; 9: 231- 33

10. Vaidhya S, Sinha. A, Narayan. S, Adhikari. S, Sabira. KC. A comparative study of fine-needle aspiration cytology and histopathology in salivary gland lesions. Journal of pathology of Nepal 2011;108-113.

11. Klijanienko J, Vielh P. Fine needle sampling of salivary gland lesions IV .Review of 50 cases of mucoepidermoid carcinoma with histologic correlation .Diagn cytopathol 1997;17:92-8

12. Yu GH, Caraway NP. Poorly-differentiated adenoid cystic carcinoma:cytologic appearance in fine-needle aspirates of distant metastases. Diagn cytopathol 1996;15:296-300.

13. Veder L, Kerrebijn JD, Smedts FM, den Bakker MA. Diagnostic accuracy of fine-needle aspiration cytology in Warthin tumors. Head Neck. 2010;32(12):1635-40

14. Dodd LG, Caraway NP, Luna MA, Byers PM. Myoepithelioma of the parotid. Report of a case initially examined by fine needle aspiration biopsy. Acta cytol 1994;38:417-21

15. Sousa J, Desa O. Salivary gland tumors : An analysis of 62 cases. Cancer 2001; 38: 38- 45.

16. Khandekar MM, Kavatkar AN, Patankar SA. FNAC of salivary gland lesions with histopathological correlation .J Otolaryngol and Head and Neck Surg 2006; 58: 246- 48.

17. Kapadia SB, Dusenbery D, Dekker A. Fine needle aspiration of pleomorphic adenoma and adenoid cystic carcinoma of salivary gland origin. Acta Cytol 1997; 41: 487- 92.

18. Lee SS, Cho KJ Jang JJ, et al. Differential diagnosis of adenoid cystic carcinoma from pleomorphic adenoma of the salivary gland on fine needle aspiration cytology. Acta Cytol 1996; 40: 1246

19. Haberal I, Golmen H, Safak MA, et al. The value of fine needle aspiration biopsy in salivary gland tumors. International Congress Series 2003; 629- 34

20. Zakowski MF. Fine needle aspiration cytology of tumors: Diagnostic accuracy and potential pitfalls. Cancer Invest 1994; 12: 505-515.

21. Chan MKM, Mc Guire LJ, King W, Li AKC, Lee JCK. Cytodiagnosis of 112 salivary gland lesions, correlation with histologic and frozen section diagnosis. Acta Cytol 1992; 36: 353- 363.

\section{*Corresponding author:}

Dr Dhananjay Shrikant Kotasthane, Department of Pathology, Mahatma Gandhi Medical college and Research Institute, Pillaiyarkuppam, Pondicherry, India Phone: +919092096244

Email: dskotasthane@gmail.com

Financial or other Competing Interests: None.

Date of Submission : 11.01.2017 Date of Acceptance : 31.01.2017

Date of Publication : 15.04.2017 